\title{
REGIÃO, REGIONALIZAÇÃO E POLÍTICAS TERRITORIAIS: ESCALAS, EXPERIÊNCIAS, ATORES
}

\author{
Región, regionalización y políticas territoriales: \\ escalas, experiencias, actores \\ Region, regionalization and regional policy: \\ scales, experiences, actors
}

\section{Claudio Ubiratan Gonçalves}

Doutorado em Geografia pela Universidade Federal Fluminense. Docente do Programa de PósGraduação em Geografia da Universidade Federal de Pernambuco. Universidade Federal de Pernambuco, Centro de Filosofia e Ciências Humanas, Departamento de Geografia. Av. Acadêmico Hélio Ramos, s/ n, CFCH- $5^{\circ}$ andar, sala 504 Cidade Universitária 50670901 - Recife, PE.

Email: claudio.ubiratan@ufpe.br

\section{Josefa de Lisboa Santos}

Doutorado em Geografia pela Universidade Federal de Sergipe. Docente do Programa de Pós-Graduação em Geografia da Universidade Federal de Sergipe. Universidade Federal de Sergipe, Núcleo de Geografia - Campus Prof. Alberto Carvalho, Itabaiana/Se. Av. Vereador Olimpio Grande, s/n, 49500-000 Itabaiana, SE.Email: josefalisboa@uol.com.br

\section{Mirlei Fachini Vicente Pereira}

Doutorado em Geografia pela Universidade Estadual Paulista, Campus Rio Claro. Docente do Programa de Pós-Graduação em Geografia da Universidade Federal de Uberlândia. Universidade Federal de Uberlândia, Faculdade de Artes, Filosofia e Ciências Sociais, Instituto de Geografia. Avenida João Naves de Ávila, n.2121, (Bloco H, Sala 1H17), Campus Santa Mônica, 38408100 - Uberlândia, MG. Email:mirlei@ufu.br

\section{Nilo Américo Rodrigues Lima de Almeida}

Doutorado em Geografia Humana pela Universidade de São Paulo. Docente do Programa de Pós-Graduação em Geografia da Universidade Federal de Pernambuco. Universidade Federal de Pernambuco, Centro de Filosofia e Ciências Humanas, Departamento de Geografia. Av. Acadêmico Hélio Ramos, s/ n, CFCH- $5^{\circ}$ andar, sala 504 Cidade Universitária 50670901 - Recife, PE.

Email: nilolimanet@gmail.com

\section{RESUMO}

O artigo trata dos trabalhos inscritos e apresentados no formato de GT e intitulado: Região, Regionalização e Políticas Territoriais: Escalas, Experiências, Atores, que foi realizado durante o XI Encontro Nacional da ANPEGE ocorrido em Presidente Prudente, São Paulo, cujo tema central foi: A diversidade da Geografia Brasileira: Escalas e Dimensões da Análise e da Ação. Os trabalhos foram seqüenciados em três blocos assim denominados: Estado e políticas territoriais, gestão e participação do/no território e avaliação de políticas públicas. E nossa intenção além de realizar uma revisão dos fundamentos do debate foi o de ressaltar "ipsis litteris" as idéias e argumentos que perpassaram os principais momentos do Grupo de Trabalho.

Palavras-chave: Políticas Territoriais; Regionalização; Região; Desenvolvimento 


\title{
RESUMEN
}

El artículo analiza los trabajos inscriptos y presentados en el formato del GT y titulado: Región, regionalización y políticas territoriales: Escalas, Experiencias, Actores, que tuvo lugar durante el XI Encuentro Nacional ANPEGE celebrado en Presidente Prudente, São Paulo, cuyo tema central fue: la diversidad de la Geografía Brasileña: Escalas y dimensiones del análisis y de la acción. El trabajo fue organizado en tres bloques denominados: Estado y políticas territoriales, gestión y participación de/en el territorio y evaluación de políticas públicas. Y nuestra intención es llevar a cabo una revisión de los fundamentos del debate para hacer hincapié en las ideas y los argumentos "literales" que constituyeron los momentos claves del Grupo de Trabajo.

Palabras-clave: Políticas Territoriales; Regionalización; Región; Desarrollo

\begin{abstract}
The article discusses the entries and presented in GT and entitled format: Region, regionalization and territorial policies: Scales, Experiences, Actors, which was held during the XI ANPEGE National Meeting held in Presidente Prudente, São Paulo, whose central theme was: the diversity of the Brazilian Geography: Scales and Analysis dimensions and Action the work was sequenced in three blocks so-called: State and territorial policies, management and participation of/in planning and evaluation of public policies. And our intention and perform a review of the fundamentals of the debate was to emphasize "verbatim" the ideas and arguments that permeated the key moments of the Working Group.
\end{abstract}

Keywords: Territorial policies ; Regionalization ; Region; Development

\section{CONSIDERAÇÕES PRELIMINARES}

O discurso formal das instituições do Estado tem afirmado que o desenvolvimento de um país não pode prescindir de uma política econômica que tenha como elemento fundamental uma estratégia de mudança estrutural. De outra maneira, a compreensão de que essa estratégia política e estrutura material a ser implantada devem ser articuladas regionalmente faz com que as temáticas vinculadas à territorialização e regionalização do desenvolvimento adquiram centralidade na agenda pública.

Assim as políticas territoriais projetadas para a última década, para além da escala do Estado nação, ganharam destaque no cenário político e acadêmico nacional e internacional. A Política Nacional de Desenvolvimento Regional do governo Lula-Dilma, como expressão de uma macro-política territorial, tem nos conceitos de região o marco teórico e de regionalização o marco instrumental para determinar, em espaço multiescalar, a ação do Estado no território nacional. 
Tal política expressa à dependência do capitalismo brasileiro da estrutura de poder do Estado que segue investindo em setores da indústria de base, de energia e infraestrutura consorciado com grupos econômicos de capital privado. Esse é apenas um exemplo de como os conceitos de região, regionalização e política territorial estão difundidos no universo da política governamental brasileira. Nesse sentido, o Grupo de Trabalho teve como propósito discutir e aprofundar experiências de desenvolvimento regional em varias escalas, tendo como parâmetro orientador os conceitos de região, regionalização, território, desenvolvimento e políticas territoriais. Foram cerca de 30 trabalhos inscritos dos quais 23 foram aprovados e 17 apresentados no XI Encontro Nacional da ANPEGE realizado em Presidente Prudente, São Paulo.

As linhas que seguem ilustram um pouco da riqueza de debate e da profundidade de reflexão teórico-conceitual e de conjuntura política que vem ocorrendo na pesquisa geográfica em nível de pós-graduação. O espaço dialógico proporcionado através do Grupo de Trabalho gestado no ENANPEGE de Goiânia e aperfeiçoado nas três últimas edições do encontro aponta para a necessidade de permanência do tratamento da questão. Qual seja? A relação: Estado, gestão e participação do/no território e avaliação de políticas públicas nas diversas dimensões do desenvolvimento. Portanto, acreditamos que os trabalhos ora enfatizados e apresentados por seus jovens pesquisadores são reveladores da complexidade sócio-econômica que se encontra o país e da responsabilidade técnico-científica em lidar com os problemas existentes proporcionais a dimensão do Brasil.

\section{ESTADO E POLÍTICAS TERRITORIAIS}

Dias \& Silva (2015) apontam dinâmicas territoriais, compreendidas como políticas territoriais de expansão do ensino superior, a partir da relação ensino presencial e EAD. O estudo indica alteração de arranjos territoriais no Estado do Mato Grosso do Sul, isto é, em escala regional de UF's (Unidades da Federação) do Brasil. O esforço se dirige sobre os seguintes dados:

- demandas regionais

- contingentes populacionais

- quantidade de instituições de ensino superior

A intenção é de leitura e contribuição da Geografia a partir da noção de (re)uso do território e fluidez regional. Neste esforço, a concepção de território-rede é enfatizada, pela qual cabia a questão: qual a dimensão geográfica da rede estabelecida no ensino superior de Mato Grosso do Sul? A indagação procura dimensionar a relação da formação profissional para o mercado de trabalho com a requalificação do território. 
A atualização referencial do trabalho se pautou em autores nacionais e estrangeiros recorrentes à geografia brasileira Dias \& Silva (2015, p. 03) buscando a compressão das articulações territoriais por meio de redes, sobretudo urbanas, materiais e imateriais. Nesse sentido, quais modalidades de regionalizações "o ensino toma como estratégias locoregionais no estado"? Em termos de dinâmicas territoriais, "como se estruturou e ainda se estrutura a rede de ensino superior em Mato Groso do Sul"? Quais os desdobramentos multiescalares no território deste estado? Essas questões buscaram compreensão de "morfologia e tipologia da rede estabelecida por meio da relação entre os pólos e suas respectivas matrizes, tanto internas - instituições sul mato-grossenses - como externas instituições oriundas de outras regiões do país". Qual o papel de novos meios midiáticos de tecnologia de informação nestas dinâmicas? Todas estas questões trouxeram aportes significativos na compreensão histórica, pré-capitalistas e capitalistas, das redes geográficas.

No que se refere à sua operacionalização, a pesquisa é delineada e consubstanciada pelas matrizes e seus respectivos campi das IES instalados/territorializadas em 22 cidades das 78 que atualmente compõem Mato Grosso do Sul (articulações internas), como se apresentam a seguir:

a. UEMS (Universidade Estadual de Mato Grosso do Sul) e UNIGRAN (Centro Universitário da Grande Dourados) com sede em Dourados;

b. UFMS (Universidade Federal de Mato Grosso do Sul), UNIDERP (Universidade para o Desenvolvimento do Estado e da Região do Pantanal), UCDB (Universidade Católica Dom Bosco) e o IFMS (Instituto Federal de Mato Grosso do Sul) todas com sedes em Campo Grande

O estudo amplia a noção de política territorial para além do cenário mais tradicional de planejamento regional de grandes eixos tais como ZEE, PACs, Zoneamento Costeiro, PNRH, SNUC, Transposição do Rio São Francisco, e etc., redimensionando a visão também para a noção de território-rede, pela qual também se pode medir, además dos usos do território, sub-elementos estruturadores tais como contingentes populacionais e quantidades de novas instalações de unidades de ensino superior.

Vilarim \& Gonçalves (2015) demonstram o Semi Árido como discurso de região problema para o Estado regional/nacional, apontando a ideologia da problemática natural - escassez de chuva - praticamente como um absoluto da causa da pobreza.

Nesse sentido, o trabalho põe em relevo, em leitura histórica recente, transformações estatais associadas ao capitalismo do século XXI , e que desnuda articulações institucionais 
de escala nacional tal como o mobilizador Projeto de Integração Nacional com a região do semi-árido Petrolina - PE e Juazeiro - BA, típicas cidades gêmeas.

O objetivo é entender o impacto da nova divisão social do trabalho, articulada a grandes projetos de recorte territorial, no fenômeno da migração e sua relação com a dilapidação do trabalho camponês pré-existente na região em questão. A análise regional aponta, portanto, para fragmentações do lugar muitas vezes invisibilizada pelo discurso de necessidade desenvolvimentista.

Percorre-se, portanto, também a forma do processo desenvolvimentista usada para o Vale do São Francisco sinalizando a recorrência de "perímetros irrigados" como conceito-recorte territorial vertical, pelo qual a divisão social do trabalho se insere desequilibradamente em benefício do capital e expropriação do trabalho.

O levantamento histórico vai percorrer a geografia dos perímetros implantados, indicados ao longo de marcos temporais e suas respectivas alterações verticais no território. Como conseqüência destes processos, aponta-se para dramática modificação no mundo do trabalho existente na 'região Petrolina-Juazeiro', impondo-se graus de especialização verticais.

A modificação do mundo do trabalho rastreada faz por demonstrar o aparecimento de novos contornos locais, como por exemplo, a re-estigmatização regional pelo qual se abandona a idéia de região-atraso para região pólo atrativa migratória modernizada, o "oásis do sertão" produzindo novas alienações no mundo do trabalho, concentração de terras e aguda divisão social do trabalho.

A pesquisa traz a crítica ao arranjo desenvolvimentista articulador, chamado de desenho territorial, das três escalas de esferas governamentais (federal, estadual, municipal). Assim, a idéia de regionalização se revestiria de caráter dicotômico: fragmenta e integra. A fragmentação se dá na simples diferenciação, na delimitação do recorte territorial; já a integração aponta que tal recorte pertence a um todo, é parte de uma totalidade.

Visu \& Abreu (2015) realizam uma avaliação qualitativa que articula políticas de escala nacional e seu rebatimento regional, com o recorte no Programa Territórios da Cidadania. O objetivo de Política Pública desta articulação de escala seria a transformação de áreas com baixo IDH e, ao mesmo tempo, com predomínio de populações indígenas e quilombolas. Nesse sentido se avalia planos de Estado e Desenvolvimento Territorial.

O recorte do referido estudo se debruçou sobre territórios rurais incorporados no sentido de aplicar maior abrangência e transcender competências e possibilidades do Ministério do Desenvolvimento Agrário, em área de recorte do Extremo Sul de Mato 
Grosso do Sul, sobre uma área-recorte batizada de Território Cone Sul.

O estudo capta contribuições teóricas de geógrafos a planos de Governo Federal, tais como Bertha Becher e Rogério Haesbaert, sobretudo na orientação de PNOT. É uma investigação que apresenta dois maiores eixos de abordagem:

1. O Programa Territórios da Cidadania e o Desenvolvimento Territorial

2. O Território Cone Sul e a participação “inclusiva” no Colegiado de Desenvolvimento Territorial (CODETER)

"O Programa Territórios da Cidadania tem uma proposta de gestão social (participativa), de inclusão dos sujeitos do território para um planejamento conjunto" Visu \& Abreu (2015, p. 03). No entanto, o estudo aponta que a ampliação do debate sobre a gestão participativa, na verdade, endossa ideologia neoliberal na medida em que apresenta a retração e menor envolvimento do Estado em políticas públicas. Este processo confirmaria, igualmente, aprofundamento da divisão social do trabalho entendendo a participação em bases mais restritivas e seletivas, sedutora tanto de conservadores como 'progressistas'. Seria a chamada rubrica de 'pluralismo de bem-estar' ou 'bem-estar misto, em um mix público-privado.

Aponta-se o contraditório do processo acima na medida em que a chamada maior participação se defronta com a modalidade de capitalismo que engendraria aprofundamento de controle de gestão por órgãos de governo criados especificamente para tal processo, tais como MPF, CGU, TCU e outros. O movimento do contraditório também modifica o conceito de território aplicado nas políticas de ordenamento territorial, tal como no caso dos territórios da cidadania.

Desse modo, a relação teoria/prática engendrou articulações de escalas e instituições como Ministério da Integração (MI), Política Nacional de Desenvolvimento Regional (PNDR) e PNOT. E no caso, com divergências históricas no âmbito da política pública sobre o conceito de território.

O Território do Cone Sul (TCS) é considerado estratégico e de importância geopolítica pela sua conexão e presença na fronteira Oeste com o Paraguai e a Leste com o estado do Paraná, enfatizando-se também a bacia hidrográfica do Rio Paraná.

Além do sentido de estratégia presente, há igualmente a perspectiva de reversão do baixo grau de IDH e outros indicadores de pobreza, entendidos como conseqüências de políticas neoliberais de governos anteriores. 
O estudo de Visu \& Abreu (2015) busca desnudar, tendo como pano de fundo o cenário estratégico acima, os sentidos de participação social em escala local (regional) a partir das relações empreendidas entre TCS e o Colegiado de Desenvolvimento Territorial (CODETER), pelo qual se infere que os representantes governamentais é que movem o CODETER, pois nem a presença efetiva da população atendida no colegiado garante participação efetiva pelos diferentes graus de expressão e força dos chamados atores (conforme o Programa designa), configurando o que pode ser entendido como o "devaneio da participação", quando a força pende, em recorrência, para o lado hegemônico do agrupamento.

Assim, a pesquisa de Visu \& Abreu (2015) pode considerar que as articulações de escalas envolvidas constituem âmbitos de representatividade e poder (capacidades), cujos interesses e respectivas forças interferem na construção do território. Considera-se uma relação de difícil equacionamento, por um lado, mas pelo qual se propõe requalificar a apropriação, por parte dos sujeitos (além de 'atores') a partir de suas bases.

O estudo de Quirino \& Guimarães (2015) busca caracterizar o Plano de Desenvolvimento Regional (PDR) como instrumento de Política de Governo objetivando planos de desenvolvimento de dimensão ambiental conservacionista.

O trabalho pretende demonstrar compreensão do mundo e suas contradições. Nesse sentido, buscou-se abordar o PDR em Mato Grosso do Sul, caracterizando as transformações ocorridas no território desde a relação do PDR com o processo de desmembramentos territoriais. Nesse sentido, discute-se noções de preservação ambiental, conservação ambiental e política ambiental bem como processos de degradação ambiental.

A metodologia apresentou levantamento de dados socioeconômicos oriundos da Secretaria de Planejamento de Mato Grosso do Sul e reconhecimento de campo realizados entre outubro de 2014 e janeiro de 2015. Decorre que os resultados do trabalho demonstraram que houve uma disparidade entre os objetivos pretendidos em relação à previsão do PDR.

Com efeito, o trabalho conclui que a desterritorialização da Região Nordeste do Mato Grosso do Sul sofreu amplo impacto da pecuária intensiva e de confinamento, da agricultura mecanizada, monoculturas e policultivos de plantio direto, redundando dentre outros impactos em intensos processos erosivos e de assoreamento de canais fluviais.

Martins \& Cleps Junior (2015) abordam políticas de conservação da natureza sob o estruturado arcabouço jurídico e normativo SNUC (Sistema Nacional de Unidades de 
Conservação), estruturação demarcadora de categorias de UCe definidora de modalidades específicas de planejamento e manejo.

Desse modo, o estudo aponta que a articulação de UC's em Mosaicos apresentaria a proposta de tornar indissociável políticas de conservação da natureza acompanhada de mecanismos alternativos de desenvolvimento, planos de desenvolvimento, tal qual o DTBC, a fim de amealhar também as populações envolvidas no recorte territorial proposto.

Assim o estudo se debruça sobre o Plano DTBC do Mosaico Sertão Veredas Peruaçu, implantado no Norte de Minas Gerais, margem esquerda do Rio São Francisco, divisa com o Estado da Bahia.

A gestão integrada e participativa do DTBC é percebida como força normativa de estruturação que disporia sobre a necessidade conservação da biodiversidade e valorização da sociodiversidade com desenvolvimento sustentável vista em escala regional.

O trabalho, portanto, procura desenvolver o conceito do "participativo" a partir desta estruturação normativa e das proposições de Edital selecionador de Projetos de Mosaico de UC's. A validação conceitual demonstra, assim, as diversas modalidades comunitárias participativas previstas (sindicatos, associações, cooperativas, ONGs, e etc.) associadas ao DTBC como mecanismo promotor da possibilidade cultura-natureza e desenvolvimento, uma vez que articula com cadeias produtivas conservacionistas.

Outra indicação que o estudo traz é demonstrar que o DTBC é uma modalidade de ordenamento territorial, relacionando o lugar (região) com o Estado, nesse sentido, por meio de diversas mediações: comunitárias, acadêmicas, terceiro setor.

A partir desta situação estruturada e ordenada, o estudo interpreta o recorte em questão como modalidade de "biorregião", tendo o cuidado de se apoiar em autores que afirmam a percepção do ecúmeno habitado e seus sentidos de territorialidade, modo de vida e lugaridade (terra natal) no processo de construção da biorregionalidade.

No entanto, fica clara a dimensão política e ordenadora do processo, pois há a previsão e aplicação de capacitações capazes de trazer a modificação do mundo do trabalho existente (Vilarim \& Gonçalves, 2015), entendida como "alterações de práticas” para atendimento de objetivos propostos no DTBC.

A partir deste dimensionamento do processo, o estudo se debruça sobre as especificidades estabelecidas no DTBC do Mosaico de UC's Sertão Veredas Peruaçu. Assim, aponta-se os principais sujeitos e instituições envolvidas, bem como os principais eixos de 
trabalho propostos tais como o Extrativismo Vegetal Sustentável que é exemplificado para reforçar a idéia de Planejamento Biorregional.

Em termos de estado da arte, o estudo se coloca em debate em alguns pontos como o conceito de "participação" (Visu \& Abreu, 2015), a questão da alteração do mundo do trabalho local (Vilarim \& Gonçalves, 2015) e entendimento de outra perspectiva de sentido do planejamento regional de política ambiental, apontadas em pesquisas anteriores como, por exemplo, Nilo Américo Lima (2008), para a implantação de Mosaico Sertão Veredas Peruaçu.

O estudo de Silva (2015) propõe-se a um esforço de compreensão de articulação de escalas, tomando como mediação o Estado Moderno, considerado aqui como instituição global com especificidades materiais locais e históricas.

Ficam, portanto, estabelecidos alguns pressupostos orientadores do trabalho:

- O papel do Estado Moderno como instrumento de regulação das relações mercado e trabalho;

- O capitalismo como modo de controle sociometabólico, apontando-se a abrangência de escala.

- O papel de mediação/repressão do Estado Moderno sobre conflitos de classes, pelo qual se passaria ideologicamente a noção de soberania nacional.

O Estudo avalia estas premissas a partir de um recorte na América Latina, propondose a verificar o avanço do capital sobre "fundos territoriais" ou "áreas não produtivas" em países da América Latina, o que significa, dadas as particularidades continental, na expropriação de povos tradicionais, terras, e exploração de trabalhadoras e trabalhadores. Nesse sentido, o trabalho procura não correr o risco de interpretar o capitalismo como uma unidade comandadora absoluta do Estado Moderno.

Deste modo, o trabalho estabelece questões fundamentais. Uma primeira se refere à compreensão do Estado Moderno: qual o seu fundamento? Em que bases se estabelecem? Quais funcionalidades? Quais relações socioeconômicas permeariam sua formação?

Percorre-se, com apoio em autores (Mascaro; Harvey;Holloway; Mészáros)tanto as bases fundantes do Estado como também se desnuda esferas de controle do capitalismo mediado pelo Estado Moderno, caracterizando-se engrenagens de articulação e poder. Ao mesmo tempo, afirma-se a possibilidade de resistência diária, inclusive, a este processo. 
Em sua funcionalidade, o Estado Moderno é caracterizado como "forma incontrolável de controle sociometabólico" e "estrutura totalizadora de controle" (Silva, 2015, p. 05) que escaparia do controle humano. A leitura é crítica, desnaturalizando o processo na medida em que se aponta que neste processo a produção e o controle estariam isolados entre si. As implicações seriam profundas atingindo determinações estruturais que seriam indispensáveis a reprodução capitalista.

Fica, entretanto, a questões de particularidades. Mobiliza-se, para compreensão do processo de escala global na América Latina, noções como, por exemplo, da "Teoria da Dependência" que coloca a relação de centralidade-periferia, bem como o papel da América Latina na Divisão do Trabalho da totalidade mundial. Nesse sentido, aparecem os recortes sobre commodities, extrativismos, acumulação por espoliação.

As possibilidades de resistências e rupturas são apontadas no estudo, vistas em protestos, pressão social, rejeição social bem como em estratégias e objetificações de retomada de "direitos roubados".

O estudo apresenta um debate articulado e aprofundado entre a pesquisadora e reconhecidos autores mencionados acima, com objetivos de compreensão da reprodução capitalista e desnaturalização das diversas mediações de controle da relação mercadotrabalho, bem como a conflitividade da luta de classes presente.

Acosta (2015) apresenta estudo em que se propõe uma revisão da conectividade entre figuras regionais e políticas territoriais, de modo que tal revisão proporcione uma leitura de processos territoriais, com periodização e reconhecimento da complexidade e conflitualidade da situação. Assim, entrelaçam-se regionalização e políticas territoriais na proposta de trabalho.

Busca-se, neste sentido caracterizar o ordenamento territorial colombiano, concentrador de população e ações de Estado em área andina e caribenha, o que resultaria em quase metade do espaço nacional da Colômbia não integrada ao Projeto de Estado Nação neste país fronteiriço. A região de Orinoquia se enquadraria nesta desintegração.

As chamadas figuras regionais caracterizariam as diferentes denominações regionais atreladas a um somatório de políticas territoriais que buscariam descentralização administrativa e desde o final do século XX, como modo de atacar as assimetrias entre região central, subcentrais e periféricas.

Uma primeira característica do trabalho denominacional atrelado ao ordenamento territorial em vigor seria a delimitação natural da região, isto é, critérios somados para 
reconhecer continuidades e homogeneidades regionais ou rupturas e diferenciações de áreas. Assim, entraram em jogo:

- o critério das águas: bacias binacionais, estruturas geológicas e tipos de águas (critério ponto de partida);

- o critério político-administrativo: reconhecedor de 05 grandes regiões naturais;

O estudo avalia que o critério natural é capaz de delimitar diferenciações regionais, porém, não seria suficiente pois corre-se o risco de tornar invisível outros elementos econômicos e sociais de produção.

Deste modo, propõe-se o conceito de "organização espacial" por ser capaz de expressar o trabalho humano acumulado, um espaço socialmente produzido e dependente, portanto, da ação de Estado. Assim, apareceria a figura dos Territorios Nacionales (TN) como território mas longíquos da capital federal da Colômbia ou de centros urbanos. Seriam, os TN territórios considerados de escassa população, sendo esta predominantemente indígena. Essas regiões receberam diversos atributos ideologizados, negativos, no imaginário urbano central.

Os TN formaram figuras regionais desde a metade do século XIX até a proclamação da Constituição Política de 1991, pela qual todos os TN se converteram em Departamentos. No entanto, "la segregación de los TN contrasta com la concentración de la población y de las acciones estatales em las regiones Andina y Caribe, condición que se reproduce aun em la actualidad." (Acosta, 2015, p. 05)

Todavia, a região estudo de caso deste trabalho, Orinoquia, converteu-se na principal bacia migratória de deslocamento populacional do período conhecido como "La Violencia", um período de enfrentamento bipartidarista. Este fenômeno atingiu amplamente a relação urbano-rural na conversão populacional entre áreas.

Um novo período, entretanto, reequilibra as forças e tem o marco de Consejos Regionales de Planificación Política Económica y Social - CORPES, que objetivaria centralização política e descentralização administrativa a partir da Ley 76, de 1985, acompanhado o enfoque neoliberal.

O estudo de Acosta (2015) transpõe-se entre periodizações geográficas e alcança o que se denomina o trânsito ao século XXI e suas políticas territoriais com consequências para a figura regional. Deste modo, percorre-se Planos de Desenvolvimento Nacional e seus interesses de integrar as regiões com a economia nacional, destacando-se o enfoque em atividades primárias, situação que foi vista anteriormente na interpretação de Silva (2015) para a América Latina, pela qual se apontou para a "acumulação por espoliação". 
A figura regional, deste modo, que é apresentada ideologicamente seria a configuração de Regiones de Planificación as quais estariam de acordo com a Constituición Nacional de 1991 e Ley Orgánica de Ordenamiento Territorial. Estas relações são interpretadas com uma reengenharia de planejamento com propósitos desenvolvimentistas e que abriram o caminho para novos agentes de influência sobre os territórios, devidamente caracterizados pelo estudo em questão, tendo como pano de fundo a contínua e histórica tensão entre impulsos descentralizadores perdedores e a centralidade física, política e administrativa reinante na Colômbia.

\section{GESTÃO E PARTICIPAÇÃO DO/NO TERRITÓRIO}

Santos (2015) trata do APL de móveis da Região Metropolitana de São Paulo (RMSP). A questão central gira em torno de como o território responde, através de uma política setorial e articulação de agentes em várias escalas, a nova regulação flexível, aproveitandose da já consolidada formação regional, que tem em seu espaço um legado histórico como a maior aglomeração industrial do país, para auxiliar na difusão de informações e favorecer as indústrias moveleiras organizadas no APL.

A região do $\mathrm{ABCD}$ passou por profundas transformações na sua estrutura econômica. Inicialmente incorporada por grandes empresas montadoras de automóveis, metalúrgicas e do ramo químico, sofreu sucessivas adaptações e reestruturações através de novas diretrizes da política regional e se voltou para micro, pequenas e médias empresas com a constituição de APLs no inicio dos anos 2000. As adaptações dos agentes econômicos a um novo regime de acumulação flexível também foram combinadas com uma regulação também flexível. E a reestruturação espacial foi acompanhada por criação de instituições regionais para coordenar a ação dos novos agentes em busca de novas estratégias diante do processo de flexibilidade econômica.

Finalmente, a introdução de novas articulações políticas e normas territoriais na região do $\mathrm{ABCD}$ desencadeou novo arranjo carregado de novos sentidos e novos conteúdos na complexidade institucional da orientação econômica ora estabelecida.

Oliveira \& Fernandes (2015) enveredam pela discussão das interações entre os grupos de pesquisa em Engenharia Química e as empresas dos diversos setores econômicos. Apresentam como problemas centrais a implantação das universidades no Brasil e sua relação com a produção de ciência, tecnologia e inovação (CT\&I) e a questão da interação entre as universidades e as empresas, analisando a sua distribuição espacial no território brasileiro. Dentre as constatações possíveis do trabalho, os grupos de pesquisa têm dificuldades em interagirem com as empresas, pois muitos não possuem interesses 
em inovar. Há certa desconfiança entre as universidades e as empresas, sobretudo por possuírem objetivos e características distintas, o que colabora para o distanciamento. As dez empresas brasileiras mais interativas, em sua maioria estatais, procuram se relacionar com os grupos de pesquisa das engenharias, além de possuírem núcleos interno de pesquisa, desenvolvimento e inovação (PD\&I), procuram as universidades para a obtenção de conhecimentos que não dispõem internamente.

Concluem que os grupos de pesquisa, assim como os seus relacionamentos com o setor produtivo, estão localizados com maior intensidade na região sudeste. Há uma concentração por conta de uma acelerada dinâmica econômica, como também presença das principais universidades vinculadas ao mercado, empresas e das bacias de petróleo mais produtivas, embora os grupos de engenharia química também interajam com empresas de outros setores econômicos.

Leite (2015), realiza um trabalho nos moldes da geografia histórica para tratar analiticamente do desenvolvimento socioespacial da cidade de Sorocaba, São Paulo, e suas repercussões para o movimento geral do processo de mundialização do capital. Fazendo uso dos quatro conceitos de Santos (2014): formas territoriais, as estruturas, a função e o processo (tempo) problematiza a dinâmica interna da cidade com as demandas externas da produção social e econômica, onde evidencia o papel da cidade no movimento de expansão da economia paulista.

As marchas tropeiras materializaram a expansão das redes viárias brasileiras, um certo tipo de estrutura que tinha como função a integração do território e a viabilização da circulação de fluxos de produção, capital e mobilidade social internos. Neste sentido, o avanço das rotas pelas tropas bandeirantes provocaram o dinamismo e formavam nós de rede que integravam pontos da região Sul, Sudeste e Centro-Oeste do Brasil com as cidades, vilas e aldeamentos, formados nesses movimentos, as capitais regionais que eram capazes de direcionar a circulação para toda unidade nacional, até mesmo para as regiões portuárias onde as mercadorias poderiam se direcionar para outros pontos do globo, como foi com o café no século XIX.

De acordo com o autor, assistimos em Sorocaba nos dias atuais uma nova frente de expansão. São identificadas estratégias de incorporação de valor na terra, que surgiram fundamentados sob o discurso da melhoria da qualidade de vida, sustentabilidade ambiental, integração de transportes, etc., que na verdade favorecem principalmente os interesses individuais dos agentes imobiliários que vem transformando a cidade num verdadeiro canteiro de obras, especialmente projetos vinculados a condomínios fechados. 
No ensaio de Geografia Regional de Almeida (2015) A região do Bico do Papagaio é apresentada como uma zona de confluência com os estados do Maranhão e do Pará, formando um canal de acesso, via Belém-Brasília, para pessoas, mercadorias e informações do Centro-Sul ao Norte do Brasil. Desenvolve os conceitos de regionalização como instrumento de investigação e espaço regional como expressão de continuidades e descontinuidades físicas e sociais.

No quadro Mesorregiões Diferenciadas do Ministério da Integração Nacional trata as regionalizações possíveis para a região do bico do papagaio e discute as sobreposições dos interesses políticos e das intencionalidades econômicas que fundamentam a existência de mais de uma regionalização para áreas físicas sobrepostas. Portanto, nem sempre a finalidade administrativa coincide com a finalidade da política pública elaborada pelo Estado. Assim, conclui-se que personificar, recortar, dividir, interferir num espaço construído historicamente por fatores também situados historicamente, é tarefa difícil, principalmente porque o objetivo perpassa quase sempre por uma idéia que visa planejamento e ordenamento. As regionalizações propostas para o Bico do Papagaio, bem como qualquer outra forma de regionalizar, podem apresentar variações em função da finalidade a que se propõem a atender.

\section{AVALIAÇÃO DE POLÍTICAS PÚBLICAS}

A análise regional também apresenta sua dimensão urbana quando Neto \& Salgado (2015) resgatam o debate acerca do papel da metrópole na polarização regional formando uma rede urbana extensa. Ao tratarem dos casos de Goiânia e Brasília, os autores chamam atenção para a formação de centros urbanos por estratégias geopolíticas, debate amplamente realizado pela produção geográfica brasileira na segunda metade dos anos 1970 e anos 1980 . Grandes cidades, sedes de poder político, que ademais concentram além da burocracia governamental as decisões e condições da reprodução do capital das empresas, instituições financeiras e comerciais. Na rede urbana que envolve o território goiano, a centralidade de Goiânia, conforme destacam com ênfase associa-se à sua condição de centro comercial e financeiro, sobretudo, que além de deter os privilégios de ser sede administrativa do poder estadual - podendo utilizar maior volume de recursos públicos em infraestrutura e concentrar funções urbanas, atrai população e investimentos de capitais e drena recursos do espaço agrário. De acordo com os autores, todas essas funções e interações direcionadas para a capital estadual impedem o aparecimento de centros intermediários e expõem a sua condição de polo regional. 
Tavares \& Oliveira (2015), optam pela análise das dinâmicas regionais relacionadas ao movimento pendular ou mobilidade populacional ocasionada pela busca de oportunidades educacionais na Região Norte do Estado do Rio de Janeiro. Para as autoras, esse quadro se dinamiza nas duas últimas décadas expressando-se como elemento de articulação regional especializando-se em determinadas aglomerações urbano-regionais.

A ampliação da oferta de ensino de diferentes níveis, sobretudo o ensino técnico e superior em espaços específicos, nas redes pública e privada em Campos dos Goytacazes, além da dinâmica econômico-social gerada pela indústria petrolífera são responsabilizadas produziu formas novas de mobilidade na região. A produção e os royaltes do petróleo na Bacia de Campos, gerando trabalho e impacto nas rendas, associada ao aumento das receitas dos municípios são condições que favoreceram a mobilidade para estudos, já que há uma oferta de bolsas de estudos por parte dos governos locais que permite à população cursar o ensino superior em outros municípios, quando os cursos não estão presentes onde residem.

Os dados do IBGE de 2000 e 2010 são utilizados para ratificar a presença e significado dos fluxos migratórios diários para trabalho e estudo, de modo a comprovar a importante dessa mobilidade para o dinamismo da região Norte do Rio de Janeiro.

O surgimento de novas atividades econômicas locais e às mudanças no mercado imobiliário em função da necessidade de habitar a cidade por parte de um conjunto de estudantes que não podem voltar para os seus municípios, seja pela carga horária dos estudos, seja pela comodidade de morar próximo dos estudos faz aumentar o número de domicílios do tipo pensão, república para serem alugados pelos estudantes.

Como desdobramento dessa mobilidade estudantil, sobretudo, observa-se que os movimentos pendulares regionais impactam na dinâmica urbana na região, assim como na maneira como a população é afetada pelas mudanças na economia e no mercado de trabalho, mostrando que não é possível entender os estudos urbanos e regionais sem considerar as mudanças na estrutura produtiva, no mercado de trabalho, no mercado imobiliário, e no comportamento da população e suas necessidades de mobilidade.

O estudo apresentado por Andrade (2015) reafirma a atualidade dos estudos de políticas públicas com enfoque territorial. $\mathrm{O}$ autor, ao analisar a dinâmica do modelo de desenvolvimento regional na economia espacial de Mossoró ancorado na agricultura irrigada de frutas tropicais, chama atenção para a imprescindibilidade de observar a dinâmica regional no contexto da mundialização do capital. Sua tese é a de que o caráter singular que as atividades econômicas assumem nos lugares elucida sua relação com outros sítios, caracterizando os espaços produtivos regionais e no caso do Rio grande do Norte, a 
especialização produtiva no cultivo de frutícolas tropicais irrigadas destinadas ao mercado externo acontece pontualmente em áreas com maior capacidade de respostas aos interesses do capital. Outro elemento que comprova essa imbricação é a dependência do capitalismo nacional à dotação de infraestrutura e concessão de crédito estatal para implementação desses empreendimentos.

Nesse cenário, há uma centralidade de Mossoró na hierarquia da produção de frutas, que se estabelece por um conjunto de ações do Estado que segue investindo em infraestrutura hídrica e oferta de crédito direcionado à agricultura irrigada, dessa maneira, segue beneficiando a elite do agronegócio ao tempo que situa o munícipio como difusor desse desenvolvimento para sua área de influência, inclusive nas escalas estadual e regional (Nordeste), atraindo pessoas e capitais de outras cidades e estados vizinhos.

A medida que a agricultura é evocada a conduzir o processo de acumulação do capital, com densidade técnica e informacional, conduzindo uma reconfiguração na dinâmica produtiva sem romper com a manutenção de velhas estruturas de poder, tem-se como desdobramento, além da acumulação concentrada da riqueza produzida, vastos bolsões de pobreza, em especial na área periurbana e rural dos municípios produtores.

Blum e Flagra (2015) adotam o conceito de biopolítica para analisar a maneira através da qual se constituem os limites de circulação, liberdade e poder no espaço a partir do Anel de Integração no Paraná, Brasil. Trata-se de explicar a constituição e manutenção de redes logísticas, a circulação de riquezas e a administração de territórios com foco na produção econômica. Os autores dão destaque à importância do Anel de Integração como um tipo de administração territorial que, ao se basear na circulação sobre o espaço, apresenta-se como um bom exemplo de tentativa de administração do território através do controle da circulação.

A rede logística pode ser entendida como a representação de relações de poder que ainda se delineiam no Paraná. O debate sobre poder é fundamentado em Michel Foucault (2008, 2014) e Claude Raffestin (1993 [1980]). A intenção é explicar as relações de poder que permearam as ações do Governo estadual, considerado um poder institucionalizado, assim como de outros grupos de pressão na estruturação da atual configuração da rede logística paranaense.

Os autores compreendem que a circulação é a imagem do poder, e permite compreender as relações de poder que se dão sobre o espaço tornado território. Diz respeito ao controle do território através da sua circulação. Isso significa afirmar que, através da privatização na forma de cobrança de tarifas de pedágio se pode falar em uma governabilidade do 
território, ou seja, a sua disciplinarização.

Alves e Magalhães (2015) analisam a regionalização da saúde no estado de Minas Gerais, relacionando-a à assistência aos pacientes portadores de câncer nos municípios que compõem a Região Ampliada de Saúde Norte - RAS Norte. O Plano Diretor de Regionalização da Saúde de Minas Gerais - PDR é um instrumento de planejamento e gestão utilizado na área da saúde. O PDR de Minas Gerais, instituído em 2002, visou a organização dos serviços de saúde em redes de atenção à saúde e considerou o fluxo da população mineira em busca desses serviços. A intenção foi garantir os princípios da equidade, integralidade, economia de escala, escopo e acessibilidade da população, em conformação com a NOAS/SUS (01/02), que estabelece a regionalização como estratégia de hierarquização e equidade na prestação dos serviços. Essas redes devem articular os pontos de atenção à saúde em territórios sanitários, assegurando uma oferta de serviços mais eficiente, efetiva e com qualidade. Dessa forma, os serviços de atenção primária à saúde devem ser ofertados no âmbito dos municípios, o mais próximo das residências, as unidades secundárias que ofertam serviços de média complexidade devem estar concentradas nas microrregiões (Regiões de Saúde), enquanto que as unidades terciárias, cujos serviços englobam a alta complexidade, concentram-se nas macrorregiões ou Regiões Ampliadas de Saúde. Nessa realidade, as unidades hospitalares que oferecem os serviços de alta complexidade oncológica concentram-se na porção sul do estado de Minas Gerais, enquanto que ao norte, somente o município de Montes Claros disponibiliza tais serviços (Idem). O setor de saúde nesse Estado reflete as desigualdades regionais, características do território mineiro, havendo nas regiões centrais e ao sul uma maior disponibilidade de serviços, equipamentos e recursos humanos especializados. Os autores propõem uma reavaliação e reestruturação constante do PDR/MG bem como estudos mais abrangentes das condições de acesso e acessibilidade dos usuários de câncer aos serviços de saúde na região, para se garantir uma oferta equitativa e eficiente desses serviços.

O estudo de Freitas (2015), sobre o processo de formação territorial no estado da Bahia, tendo Feira de Santana como recorte escalar, veio desvelar circunlóquios e práticas que materializam os poderes sustentados por instituições políticas e econômicas sobre esta escala geográfica. O estudo enfoca o sertão/território como lócus da implantação da territorialização do capital, espaço que é compreendido enquanto relação dialética, em suas múltiplas dimensões escalares. O ponto de partida é Feira de Santana, escala de análise, lugar que serviu de alicerce para a busca do conhecimento sobre a formação territorial do sertão. A construção/criação deste espaço institui um desafio para se pensar a importância econômica e política deste município que é Princesa do Sertão ao mesmo tempo em que é Portal do Sertão. 
O valor do espaço sertanejo, iniciado com a colonização é resposta à lógica mercantilista, que teve a moeda como central e a expectativa de transformar o espaço em mercadoria. O sertão foi sendo revestido de conteúdo de mercado, mercadoria não avaliada pela utilidade, pelo seu conteúdo material, mas uma forma relativa de valor. O processo de valorização, concentrado no litoral - por esse turno, permitiu a concentração dos recursos financeiros nas mãos da burguesia, que posteriormente foram utilizados para a compra dos meios de produção e exploração do trabalho, através da expropriação, ampliando a demanda por acumulação.

A depreciação do sertão, nítida nos textos da época, quando, por exemplo, os escritores, ao caracterizar os índios como os aimorés - e a Bahia está no centro desta discussão os apresentavam de forma negativa, comparando-os aos animais. Os portugueses os denominavam de Botocudos devido aos botoques de madeira ou de pedra que usavam nas orelhas e no lábio inferior.

Constatou-se que Feira de Santana, está localizada no lugar considerado vazio na observação do colonizador que aqui chegou para levar território sertanejo à Europa, prova cabal que tal condição é colocada pelo olhar estrangeiro. Sertão: descrito como vazio, o espaço repleto de seres humanos denominados índios, povos que foram arrancados da terra, no instante em que testemunhavam os desígnios da colonização. Aqui encontrados livres, foram escravizados, corrompidos, porque ao mesmo tempo, foram parceiros dos diversos aspectos desse processo.

\section{CONSIDERAÇÕES FINAIS}

Compreendemos que os trabalhos inscritos no GT - Região, regionalização e políticas territoriais: escalas, experiências, atores, refletiram o movimento geral proposto pela organização do XI ENANPEGE e dos coordenadores do própiro GT. Observamos não somente a aproximação com o tema central do evento, mas, sobretudo a inquietude que as investigações científicas suscitaram como o somatório da diversidade de escalas propostas e das ações de análise necessárias para o desenvolvimento da Geografia Brasileira.

Foram vários os pontos de vistas defendidos, as teorias pontuadas e apresentadas e as práticas dos pesquisadores na produção do conhecimento geográfico. Destacamos que coube aos coordenadores do grupo de trabalho provocar radicalmente a participação propositiva dos participantes e de correlacionar as temáticas inovadoras das pesquisas concluídas ou na fase conclusiva.

a 
Finalmente ressaltamos que a opção de estruturar este texto em três momentos, a saber: Estado e políticas territoriais, gestão e participação do/no território e avaliação de políticas públicas não refletem de modo estanque as exposições aqui elencadas. Ao contrário, nossa intenção é a de procurar traduzir as propostas individuais apresentadas e que de alguma maneira superam o próprio GT evidenciando a necessidade de sua recriação.

\section{REFERÊNCIAS}

1. ACOSTA, Yolima Devia. Regionalização, políticas territoriales y económicas em el Oriente colombiano. Presidente Prudente - SP: XI ENANPEGE/A diversidade da geografia brasileira: escalas e dimensões da análise e da ação. 09 a 12 de outubro de 2015.

2. ALMEIDA, Rutileia Lima. Geografia Regional Contemporânea do Bico do Papagaio: A Região e a Regionalização. Presidente Prudente - SP: XI ENANPEGE/A diversidade da geografia brasileira: escalas e dimensões da análise e da ação. 09 a 12 de outubro de 2015.

3. ALVES, M. O; MAGALÃES, S. C. M. A regionalização da saúde e a assistência aos usuários com câncer no norte de Minas: uma análise a partir do PDR/MG. In: Anais do XI Encontro Nacional da ANPEGE: a diversidade da geografia brasileira, escalas e dimensões da análise e da ação. Presidente Prudente, 2015.

4. ANDRADE, A. A. de. Agricultura e economia espacial em Mossoró/RN: dinâmicas e especificidade regional. In: Anais do XI Encontro Nacional da ANPEGE: a diversidade da geografia brasileira, escalas e dimensões da análise e da ação. Presidente Prudente, 2015.

5. BLUM, G. G.; FRAGA, N. C. Rede logística, biopolítica e governamentalidade da circulação no território no século XXI: o caso do anel de integração no Paraná. In: Anais do XI Encontro Nacional da ANPEGE: a diversidade da geografia brasileira, escalas e dimensões da análise e da ação. Presidente Prudente, 2015.

6. DIAS, Fernando Cesar; SILVA, Edima Aranha. O ensino superior presencial e à distância em rede em Mato Grosso do Sul. Presidente Prudente - SP: XI ENANPEGE/A diversidade da geografia brasileira: escalas e dimensões da análise e da ação. 09 a 12 de outubro de 2015.

7. FREITAS, Nacelice Barbosa. O descoroamento da princesa do sertão: de "chão" a território, o "vazio" no processo da valorização do espaço. In: Anais do XI Encontro Nacional da ANPEGE: a diversidade da geografia brasileira, escalas e dimensões da análise e da ação. Presidente Prudente, 2015.

8. LEITE, Thiago Rodrigues. As estratégias socioespaciais de desenvolvimento e a territorialização de Sorocaba. Presidente Prudente - SP: XI ENANPEGE/A diversidade da geografia brasileira: escalas e dimensões da análise e da ação. 09 a 12 de outubro de 2015.

9. LIMA, Nilo Américo (Nilo Américo Rodrigues Lima de Almeida). Conservação no cerrado, território, política pública: mosaico de unidades de conservação veredas peruaçu. São Paulo: tese de doutorado apresentada ao Departamento de Geografia/FFLCH/USP. 2008. 
10. MARTINS, Geraldo Inácio; CLEPS JUNIOR, João. Planejamento biorregional e desenvolvimento de base conservacionista no mosaico sertão veredas peruaçu, Norte de Minas Gerais. Presidente Prudente - SP:XI ENANPEGE/A diversidade da geografia brasileira: escalas e dimensões da análise e da ação. 09 a 12 de outubro de 2015.

11. NETO, O. P. A.; SALGADO, T. R. Rede urbana de Goiás: análise das interações espaciais dos centros na rede urbana.In: Anais do XI Encontro Nacional da ANPEGE: a diversidade da geografia brasileira, escalas e dimensões da análise e da ação. Presidente Prudente, 2015.

12. OLIVEIRA, Arlindo Teixeira de; FERNANDES, Ana Cristina. A Distribuição Espacial das Interações entre Universidades e Empresas no Brasil: Um estudo de caso dos Grupos de Pesquisa em Engenharia Química. Presidente Prudente - SP: XI ENANPEGE/A diversidade da geografia brasileira: escalas e dimensões da análise e da ação. 09 a 12 de outubro de 2015.

13. QUIRINO, Paola Bueno; Guimarães Valter. Políticas da desterritorialização e seus efeitos ambientais na região nordeste do estado de Mato Grosso do Sul. Presidente Prudente - SP: XI ENANPEGE/A diversidade da geografia brasileira: escalas e dimensões da análise e da ação. 09 a 12 de outubro de 2015.

14. SANTOS, Eliane Carvalho dos. A APL de Móveis da RMSP e flexibilidade: Atores e Articulações para a Regulação Regional. Presidente Prudente - SP: XI ENANPEGE/A diversidade da geografia brasileira: escalas e dimensões da análise e da ação. 09 a 12 de outubro de 2015.

15. SILVA, Suana Medeiros. Quando o galo insiste em cantar: sobre o estado moderno, a reprodução capitalista e a luta de classes. Presidente Prudente - SP: XI ENANPEGE/A diversidade da geografia brasileira: escalas e dimensões da análise e da ação. 09 a 12 de outubro de 2015.

16. TAVARES, J. M. da S.; Movimentos pendulares para fins de estudo no interior do estado do Rio de Janeiro. In: Anais do XI Encontro Nacional da ANPEGE: a diversidade da geografia brasileira, escalas e dimensões da análise e da ação. Presidente Prudente, 2015.

17. VILARIM, Mariana de Alburquerque; GONÇALVES, Claudio Ubiratan. A região de Petrolina - PE e Juazeiro - BA: notas sobre as transformações locais, os sujeitos do campo e a migração. Presidente Prudente - SP: XI ENANPEGE/A diversidade da geografia brasileira: escalas e dimensões da análise e da ação. 09 a 12 de outubro de 2015.

18. VISU, Gilson Carlos; ABREU, Silvana. O desenvolvimento territorial no território cone sul (MS): repercussões das ações do programa territórios da cidadania. Presidente Prudente SP: XI ENANPEGE/A diversidade da geografia brasileira: escalas e dimensões da análise e da ação. 09 a 12 de outubro de 2015.

Artigo recebido em 18 de abril de 2016

Artigo aceito em 18 de maio de 2016 